neath it was a large quantity of pus. Not the restige of a muscle was to be seen in any part of the thigh; and the great vessels and nerves appeared like mere cords, and were only present at intervals, and could not be traced.

\section{ON THE PHYSICAL CAUSES OF HYSTERIA.}

By Darin NFison, M.D.Edin.; formerly Physician to the Queen's Hospital, and Professor of Clinical Medicine in Queen's College, Birmingham.

Trie innumerable protean forms assumed by the strange group of diseases called hysteria, have rendered it one of the most defiant to all medical treatment. Certainly, the very name indicates that the more ancient authors recognised its origination in some disorder of the uterine functions; but, at the same time, such conclusion was rather drawn from the general fact that it was peculiar to women, than from any satisfactory investigation into the actual condition of organs which at those earlier periods were little known or understood. The advance of time, however, has always tended to narrow the list of diseases attributable to mere functional disorder, and to trace such disordered functions to physical causes more or less apparent.

Without doubting-for who could doubt?-the potent in. fluences exercised over bodily functions by mental emotion alone, which is invisible and intangible in its very nature, we yet cannot close our eyes to the fact that many deviations from health, which formerly were referred, in a very vague manner, to hysterical excitement-cachexy, idiopathic debility, and the like-are now found to depend upon physical causes, palpable, visible, and demonstrable. Witness the explication of such diseases as scurvy, aræmia, gout, and rheumatism, and the cardiac, renal, hepatic, and pulmonary dropsies-all formerly attributed to cachexy, but now traced each to its own peculiar origin, whether such origin be chemical deficiencies or redundancies in the blood, or anatomical changes of structure and deposit.

The knife of the morbid anatomist and the microscope-but, above all, the advances of chemical science-have been the main agencies in the philosophical elucidation of causes, formerly known only in their effects; but, besides such helps, we have also been greatly aided by those closer habits of investigation and reasoning that have characterised an era of which Bacon, Harvey, Sydenham, Newton, Lavoisier, Hunter, Alison, etc., have been the models. The whole tendency of such men's efforts has been to disperse unbased theories to the winds, and to ground whatever doctrines they advanced upon a series of facts clearly ascertained and capable of demonstration. Following this inductive method, I think I have observed some very minute physical causes giving rise to hysterical affections the most severe and alarming; and, under the belief that too little pains have generally been taken to unravel the reflex nervous actions constituting such disease, and too much readiness exhibited to dismiss all further thought on the matter by the trite expression "It is merely hysterical", I have adventured to draw the attention of the profession to a few points, trusting that they may move others to further inquiry and observation in the same direction.

Admitting, as I have already done, the close connection of the emotional centres with the ganglionic and other nervous expansions that invest the reproductive system through the medium of the spinal cord, I yet believe that hysterical disorders spring less from any idiopathic irritability of such emotional centres than from morbid physical irritation at the periphery of the nerves. This view is strengthened by the consideration that it is not so much women of a delicate mental organisation, if such be coupled with good bodily health, that are most subject to hysteria; but rather such as are diseased, and especially if such disease affect those organs that are most intimately associated with such emotional functions. In short, the emotional and nervous excitement which occurs, is, for the most part, a reflection from the local disorder, rather than is the local disorder consequent upon primary emotion; just as some flashing fancy of being buried alive, or covered with vermin, or otherwise tickled or irritated, may produce an emotional sense of constriction at the chest, or a fit of fidgets, or a shudder, or a feeling of superficial itching ; while the actual subjection to the outward realities themselves must give rise both to the emotional and muscular excitation: so is it to my mind with cases of hysteria. I believe that a case may now and then occur wherein the fits may be traced to emotion alone; but that the vast majority are due to sub. stantial causes. The first I should view as a partial mental derangement; the second, as the real bodily idisease; and, even if I could not discover any organic peripheral disorder, I should not be the less convinced of its existence, unless I could discern by direct or collateral evidence that there was morbid processes going on within the brain and spinal prolongation.

To illustrate my meaning practically, I shall now adduce some cases that have occurred amongst many others of a similar kind in my practice during the last few years; and, not to tire my brethren with long details of dates and changes in the symptoms, having little reference to the special point at issue, I shall merely give the salient facts, embracing the symptoms, the principles of treatment, and the results.

CASE I. Mrs. J., aged about 33, had had no children. Sne had complained of general derangement of health for several years, and had become of late much reduced, being preternaturally thin and pale, and having a haggard worn-out expression. Her special ailments, however, consisted of sn excessive leucorrhœa, the discharge approaching to the appearance of pus, great frequency of micturition, lancinating pains on passing the urine, extreme tenderness about the seat of disease, which had led to some domestic unhappiness, and severe attacks of the hysteric paroxysm, especially at the menstrual periods. All these symptoms proved to be dependent on the existence of a few very minute erectile and sensitive papillæ in the neighbourhood of the urethra and outlet of the vagina. The latter looked like caruncula myrtiformes, highly charged with vascular and nervous matter. After using the routine remedies of steel and valerian, and having soothing unguents and nitrate of silver applied in vain, I recommended the surgical removal of those minute growths. From their exquisite sensibility, the pain inflicted was sharp, but momentary; and from that period her distress has left her. She has become plump and well coloured, and is able to manage her father's business with ease.

I may just add, as a suggestive hint, that I was subsequently called into consultation regarding her mother, who was in the last stage of cancer of the womb, and who died two days or so after I had seen her. The father then stated that, in earlier life, she had suffered in a manner similar to her daughter; but that she would never consent to see any medical man upon the subject, until fearful floodings set in, and the case was. hopeless.

CASE II. Mrs. M. H., aged 52, having had no children, had ceased to menstruate for four years; but of late had been subjected to attacks of flooding, which had blanched her cheeks, and reduced her in flesh. Since these losses of blood she had become very nervous and excitable, trembled from the slightest cause, was unable to sleep soundly, and had had frequent attacks of acute hysteria, which she had never been subject to before. There were enlargement and descent of a flabby uterus, and round the edges of the os, which was very sensitive and red, there was a roughness, as of grains of sand, with patches of hard substance about the size of a split pea here and there. She was put under the tinctures of steel and of ergot, with muriate of morphia, and nitrate of silver was ordered to be applied to the cervix, and to the inner surface of the uterus. Under this treatment the hæmorrhage was arrested, and all the other symptoms along with the fits vanished.

Case III. Mrs. P., aged about 30, had had some children, who had all died, and several miscarriages. She had, for a considerable time, been the subject of severe monthly hæmorrhages, and in the intervals there had been troublesome dysuria, much tenderness, and a profuse discharge of thick pus per vaginam. Under these circumstances she had become thin, and her complexion changed to a yellowish straw colour. At the same time she grew more than usually hysterical; she could scarcely speak without crying, and the slightest contradiction or excitement brought on the actual paroxysm. She seemed to have gone from one practitioner to another, principally to those engaged in one special walk, for reasons sufficiently obvious; but it was observed that the treatment adopted by each one was almost a repetition of that of the others, and she continued the same. The cause was evidently something out of the usual course, and was found to consist in the presence of a surprising number of polypoid growths on the mucous surface, of different sizes, some having narrow necks, and others springing from broad bases. The cervix was also deeply ulcerated. The advice was, that she should have the growths removed by means of scissors, and the cervix treated with nitrate of silver. After this was done, 
she underwent a course of treatment, consisting chiefly of steel, jodide of potassium, and cinchona twice a day, and a Plum. mer's pill every night. The discharges soon ceased, the colour was restored, and the fits left her entirely. She continues well.

CASE Iv. Mrs. B., aged about 44 , the mother of six children, had repeatedly called at my house to consult me, during and after attacks of flooding at the monthly periods. The last time she came, the pallor was extreme, her pulse small and weak, and the debility and local tenderness urgent, giving rise to paroxysms that seemed to partake of the character of fainting as well as hysteria. Under great alarm I happened to be sent for, and found that, although the bleeding had stopped under the action of acetate of lead and ergot, the nervous symptoms continued urgent, and of an alarming appearance. She lay deadly pale, and unable to speak above a whisper, while much tenderness existed all over the abdomen, but especially in the neighbourhood of the uterus. She described an acute pain, like the entrance of a knife, as darting every now and then from the vulva up towards the navel and back, which induced faintness, sickness, and trembling. The slightest examination, with the view of discovering the cause, exalted this pain so much that she instantly fell into a condition of faintuess, gasping, sobbing, rolling of the eyes, clutching of the fingers, and other forms of bysteric struggling. After being under the influence of a dose of opium, however, and the same material in ointment having been applied locally, the speculum was, with some difficulty, introduced. Much pain was experienced on its passing a particular point; and there was found only slight abrasion of the cervix, to which nitrate of silver was applied. On slow withdrawal, she was persuaded to keep so composed as to remain silent, until the instrument should again pass over the tender point, when she screamed out involuntarily, and sail, "Oh, there it is!" There was then observed, hooked over the mouth of the speculum, a very small erectile body, of a crooked shape, and quite resembling a small cat's claw. On allowing it to droop down, it was found to be not far from the entrance of the vagina, and was forthwith snipped off. It was a sharp conical growth, calcified at the extremity. No pain worth mentioning occurred afterwards. The slight alcerations of the cervix healed soon, and she completely regained her original strength and colour, under a course of steel and quinine, with meat diet and porter. No floodings recurred. Under her illness she had sold her business; but has now resumed it.

CASE v. Miss H., aged about 30, well grown, and of robust appearance, of late had become what she called exceedingly nervous, and had lost her voice. It was chiefly for this latter ailment of aphonia that she came to me; and she was treated for that for a considerable time, being ordered to keep perfectly silent, to have the nitrate of silver applied to the throat once a week, while she took iodide of potassium, with tinctures of cinchona and capsicum, and chewed some mezereon root. There was a gradual amendment of the voice under these remedies; but she, by and by, made further statements regarding the extreme pains which attended menstruation, which was very sluggish, and accompanied with the casting forth of clots, and fibrinous casts from the mucous surface of the uterus. The pains brought on violent bysterical fits at those periods; so much so, that the whole family was in a state of alarm and bustle night and day during the time. It proved, in this case, that there were no growths, or any particular tenderness about the parts affected, the paroxysm consisting entirely of a grinding spasmodic agony; but the os was exceedingly small, scarcely admitting of the passage of the smallest bougie. Dilatation was advised, followed by the internal application of the nitrate of silver; after which the voice very rapidly regained its power, the menstruation became easy and natural, and no more fits occurred. She is now married, and in perfect health.

CASE vi. Mrs. Y., aged about $3 \pm$, very spare and pale, and without family, was restless and fidgety, and had very little sleep. Her appetite had failed, and she felt as if she had no strength, even for a short walk. Menstruation had become exceedingly painful, and she was aftlicted with trembling, nervousness, and hysterical excitement and depression. The slightest touch at the orifice had for some time given extreme agony; though, after that point was passed, all pain ceased. Micturition was inconveniently frequent, the vaginal tenderness was much aggravated at the monthly periods, and often, on sitting down, she had suddenly to get up again, as if from a long needle penetrating the body. In this case, a very minute pointed body, like one of the caruncula, in a state of extra vascularity, and highly charged with nervous filaments, was alone discovered. Fvery other part of the mucous surface could be traversed with the point of a caoutchouc bougie with impunity; but the moment the spot of disease was touched, the patient shrunk and called out, while the caruncle became erect. A very free application of the nitrate of silver alone served to eradicate this little growth, and all the urgent symptoms disappeared along with it. She had never been large or vigorous; but she quickly regained what original stoutness, and colour, and strength she had formerly possessed, under a course of liquor pepticus, with steel after food.

CASE vir. Miss G., aged about 22 , very tall, spare, and pale, had, as her mother described, been troubled for a great number of years with frequency of micturition, accompanied with sharp lancinating pains. These were much worse at the monthly periods, and gave rise to crying, and after also to hysterical fits. During her school years, she had suffered in the same way, though in a less acute degree; and had been frequently scolded and beaten for using, as they thought, false pretences to leave the school-room, inasmuch as she professed to be in a great hurry to pass water, while the pain made her so slow in the operation, that they could not believe in the urgency of the desire. She was also scolded for stooping, and walking at a snail's pace. She had the same stoop and slow gait when she entered my room, and her face expressec anxiety and discontent. She had had much medical attendance from time to time; but nothing had been made out dis. tinctly. One had referred the symptoms to calculi ; another to the kidney; another to the bladder; and others again to the uterus. 'The cause of the failure in a true diagnosis clearly lay in the extreme suffering of the girl under the slightest manipulation. The very thought of it had always brought on crying and hysterical excitement; and the slightest touch augmented those symptoms to struggling, shrill screaming, and convulsions of the eyes, and hands, etc., quite enough to make most people desist. By a little patience and management, however, it was soon seen, that the source of all these evils lay in a very small vascular and nervous growth, which protruded like a little bead of coral from the orifice of the urethra. It was advised that this should be removed as speedily as possible. By a little persuasion she was induced to make a firm resolve to have it destroyed. The pain caused by the forceps and scissors was very sharp; but short and effectual. The more minute fungoid growths which subsequently attempted to spring from the little wound, were completely kept in check, and annihilated by nitrate of silver. Under tonics and nutrients, her general health was afterwards restored, and all the special complaints were at an end. From long habit, she seemed to retain her stooping attitude, and peculiarly short step. For this it was advised that she should take to calisthenic exercises, or dancing. She chose the latter and is now like other young women, cheerful in mind, and easy in her gait.

CASE virr. Mrs. B., aged about 5 4 , the mother of a family, had been long troubled with acute tenderness and frequency of micturition, accompanied with sharp lancinating pains. She was much reduced in flesh under these sufferings; and so nervous and hysterical had she become, that night and day she was a source of trouble and annoyance to the gentleman who attended her, he being called out to treat these attacks at all times and hours. Having known of another case about to bo related, he examined into this one, and found the disease to be a vascular and nervous growth, like the one just described. He requested me to see it with him, when it proved to be of greater magnitude than Miss G.'s. On first exploring with a bougie, it was found to be rooted high up in the urethra, and to spring from a broad base. It was pulled down as far as possible by means of blunt forceps, and then snipped off. Bleeding was checked by nitrate of silver, and an astringent lotion was applied. At my next visit, it had fungated to a considerable extent, and looked very ugly and formidable. I almost feared we had made a serious mistake, and had interfered with some malignant vegetation that had better have been left alone. However, although the patient was thin and pale, there was no decided appearance of the cancerous tendency about her; and we again attacked the fungoid growth with the steel; and it was now to be followed up by daily bold applications of the nitrate of silver. Under this treatment for a few weeks, her peculiar symptoms left her, and she afterwards became quite full and hale.

CASE IX. Mrs. D., aged about 28, small, pale, and thin, and 
the mother of children, was first brought to me by her mother about twelve months before the special treatment was begun She had not long been confined of a baby, and was of a dejected and wasted appearance. Under an impression of consumption, she had been taking cod oil; but I could discover no pulmonary symptoms whatever; and, though the general appearance was aniemic, there was no rapidity of pulse, no redness round the teeth, nor any waxy shining round the roots of the nails - to $\mathrm{my}$ mind the most decisive symptom of constitutional phthisis, in the absence of chest-signs. I rather suspected worms in the first instance, and prescribed accordingly; but none came away. From certain symptoms being further described, I afterwards suggested that the uterus might be at fault, and ordered steel and ergot and morphia during the catamenise, which were attencled with severe pain. She was, however, naturally shy and timid; and her mother could not induce her to see me again for some six months or so. Meanwhile, the opinion of some other physician had been taken, who, while agreeing that no pulmonary symptoms were discoverable, could not shake the idea of tuberculosis from his mind, on account of her paleness and emaciation; and the cod oil had again been resorted to, though without any benefit.

At this consultation, extreme tenderness was discovered, and great nervous excitement; but, for the time being, no further treatment was adopted, beyond the use of peptic liquor, with steel and quinine, a soothing ointment of opium, and the monthly doses of ergot, etc., as above.

Several months more elapsed, when, in an extremity, I was sent for one nirht. It apyeared that her sufferings latterly had been much agrravated, especially at the monthly periods. She was fit to do nothing; enjoyed no food; had scarcely any sleep; sat crying most of the day ; and was seized with hysteric paroxysms so severely and frequently that the family medical attendant was constantly in requisition for them. It was now observable that her face was pale, sunken, and dejected; her abdomen sunk; the arms and legs reduced to skin and bone; and yet the chest was resonant and round. It was now decided that I should meet the family attendant next.morning, and go thoroughly into the cause of this state of things. One glance revealed it. There were several small warty growths around the vulva; and, on passing a small speculum with great difficuity (on account of the tenderness), ulceration was discovered at the os uteri. The latter was touched with nitrate of silver, and so were the warts for the present. Some of them were scarcely impressed either by that or by acetate of copper with sabine; and the scissors were soon resorted to, with decided success. From the pain and consequent nervous excitation, the whole could not be accomplished at once; but, after a few operations, all were removed, and no more tender. ness existed. All the while, and for a time after, she took a Plummer's pill every night; and iodide of potassium, with cinchona and hyoscyamus, thrice daily. Subsequently, she had the peptic liquor, with quinine and steel; and has quite regained her strength, fulness, and colour; and is free from fits.

CAsE $x$. This young woman, aged about 26 , pale, thin, and dejected, had been suffering from painful menstruation and dysuria, accompanied with a lancinating agony along the urethra for a long time. Every month she had severe and alarming attacks of hysteria, and was described as being no sooner out of one fit than another came on. Similar fits would also sometimes supervene when she passed water. She could retain the urine somewhat longer after steel, lytta, and morphia, had been prescribel; but the pain in passing it remained the same, and the fits during menstruation continued as severe as ever. On one examination after another, nothing could be discovered beyond an extreme general tenderness, which induced fainting hysteria under the slightest touch. The vagina seemed contracted and tender; but such tenderness was nothing, as compared with the effect of introducing an elastic bougie into the urethra. On doing this, the whole body seemed electrified with an agony almost unbearable. Still nothing could be discovered of any tangible nature. Chloroform was as yet useless, because it would not enable us to make out where was the centre point of this extraordinary sensibility. At length, under the comparative quietude arising from opium, she could submit to be gently touched here and there with the soft blun point of the elastic bougie. Whenever and wheresoever touched, she flinched more or less; but it was not till I had impinged upon the left side of the orifice of the urethra, that the shriel and the convulsive agony came on. After a pause, the other side was touched, but with no such effect; yet again, on touch- ing the left, similar results followed. And now was noticed a very slight fold of erectile tissue, which seemed nothing more than a very minute reduplicature of the urethral mucous membrane. So to speak, it looked like a very, very small urethral hæmorrhoid, but sensitive beyond belief. Almost invisible as was this little growth, I felt persuaded that it was the source of the mischief, and recommended its removal. Some time was taken to consider of this step, but at leugth she made up her mind. The sensibility was so acute, that all of us felt that nothing could be effected without chloroform. This being administered, and the otler surgeons present holding the extremities, the operator made an effort to remove the body, but without success; for, the moment any approach was made, it was met by a violent resistance and convulsive recession of the body. After two or three vain attempts of the kind, he said, "I must do it in a noment, or not at all. Hold fast!" In one instant after that, the operation was completed, but accompanied with a convulsive start on the part of the patient. On recovering from the effect of the chloroform, she said she felt unconscious of pain, but had dreamed curiously, and was inclined to sing. All seemed well; but, in the course of the night, hæmorrhage set in: it was of an alarming nature, so that the operator feared she would die. On seeing her, she was blanched and voiceless, and no pulse was perceptible; but, on asking her to grasp my hand, sile did so with energy. I then had no despair of the case. Bad as it seemed, the hemorrhage was stopped; and she was ont of immediate danger. What followed, however, was tedious. Extreme debility and faintness compelled confinement to bed for a long time. Next came the slow convalescence. First, she was able to get up and sit on a chair; next she was carried down stairs, in a sort of faint; then she walked round a table, supporting her arms on it; and next used crutches: finally, she could wall: without them, and recovered her original condition, but without any dysuria, or pain, or fits. Her father was inclined to trace the complaint to small-pox, as she had a sore in that situation during the disease; but this I mention only incidentally. She is now well.

As already observed, I have given these cases simply to illustrate the truth of the principle, that very minute deviations from health at.the periphery will often induce derangements in the general nervous system of a violence and magnitude apparently quite disproportionate to the exciting cause. The importance of looking to these physical causes of hysterin is unquestionable; but, at the same time, it will be equally obvious that the inquiry cannot be entered into till all the usua remedies have failed, and, even then, only by those who have the full confidence of the patient and her family.

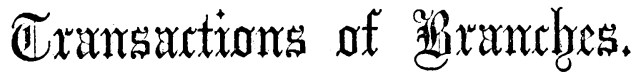

\section{LANCASHIRE AND CHESHIRE BRANCH.}

REMARKS ON TREPHINING THE SKULL: ILLUSTRATED BY A CASE.

By Arthur W. Dumvir.te, Esq., Surgeon to the Manchester Royal Infirmary.

[Rcad June 30th.]

Is these days of fondness for statistics, in which generalisations are only thought of value when drawn from a very large number of particulars, it seems almost absurd to found an essay, however unpretending, on a single case. I can only plead in excuse, first, the importance of the subject which $I$ bring before you; and second, the rarity of the cases for illustration.

Of all great surgical operations, that of trephining the skull is perhaps now the least frequently performed. Surgeons of large practice have passed through a long course of years, and have never applied the trephine; yet there can be no doubt that many lives have been saved by means of this operation; and I think it is not too much to state that some lives may have been lost because it has not been performed.

In cases of compressed fracture of the skull, with evident symptoms of pressure on the brain, especially if those symptoms have manifested themselves from the time of the occurrence of the accident, surgeons are agreed upon the plan of treatment ; namely, by means of the elevator, or Hey's saw, or the 